\title{
Kerr and Faraday effects in borate glasses
}

\author{
Adamenko D., Adamiv V., Klymiv I. and Vlokh R. \\ Institute of Physical Optics, 23 Dragomanov St., 79005 Lviv, Ukraine, \\ e-mail: vlokh@ifo.lviv.ua
}

Received: 27.09 .2010

\begin{abstract}
Electrooptic Kerr and magnetooptic Faraday effects are studied in $\mathrm{LiKB}_{4} \mathrm{O}_{7}$, $\mathrm{Li}_{2} \mathrm{~B}_{6} \mathrm{O}_{10}$ and $\mathrm{LiCsB}_{6} \mathrm{O}_{10}$ glasses. The corresponding quantitative coefficients are determined for the wavelength of $632.8 \mathrm{~nm}$. It is shown that the above compounds can be used as electrooptic and magnetooptic materials which are highly resistant to powerful optical radiation and transparent in the ultraviolet spectral range.
\end{abstract}

Keywords: borate glasses, electrooptic Kerr effect, Faraday effect

PACS: 78.20.Ls, 78.20.Jq, 42.70.Ce

UDC: $535.55,535.56$

\section{Introduction}

It is known that anhydrous borate crystals are resistive to powerful optical radiation and manifest a wide range of optical transparency, extending from the vacuum ultraviolet as far as to the infrared spectral region [1-5]. Non-centrosymmetric representatives of this family are efficient nonlinear optical materials [2, 5, 6-11] and also manifest high optical resistance [12]. They are widely used in parametric optical oscillators as functional elements $[13,14]$. Recently we have shown that the borate crystals may also be used as acoustooptic materials, in particular for acoustooptic operation of laser radiation in the short-wavelength spectral range [15-23]. We should also notice that the acoustooptic interactions do not require a lack of centre of symmetry, being possible even in the isotropic glasses. Besides, the borate glasses are ecologically promising materials that do not contain lead ions.

The glasses of different chemical compositions have been successfully used in various optoelectronic applications, in particular in acoustooptics (see, e. g., [24-29]). In the work [30] it has been shown that both the pure $\mathrm{Li}_{2} \mathrm{~B}_{4} \mathrm{O}_{7}$ glass and the borate glasses doped with $\mathrm{Cr}, \mathrm{Co}, \mathrm{Eu}$ and Dy ions can be successfully obtained while melting them at $1223 \mathrm{~K}$ and then overheating up to $1423 \mathrm{~K}$. It is worthwhile that the pure $\mathrm{Li}_{2} \mathrm{~B}_{4} \mathrm{O}_{7}$ glass is transparent down to $190 \mathrm{~nm}$ [30]. In our recent work [31] it has been demonstrated that the borate glasses such as $\mathrm{LiKB}_{4} \mathrm{O}_{7}, \mathrm{Li}_{2} \mathrm{~B}_{6} \mathrm{O}_{10}$ and $\mathrm{LiCsB}_{6} \mathrm{O}_{10}$ are transparent down to the wavelengths of $165-190 \mathrm{~nm}$. Moreover, they are very resistant to a powerful laser radiation (e.g., the laser damage threshold for the $\mathrm{LiCsB}_{6} \mathrm{O}_{10}$ glass is equal to $24.7 \mathrm{GW} / \mathrm{cm}^{2}$ ). We have also shown that the acoustooptic 
figure of merit for the glasses under test can reach very high values. In particular, this figure is as high as $M_{2}=(201 \pm 104) \times 10^{-15} \mathrm{~s}^{3} / \mathrm{kg}$ for the $\mathrm{LiCsB}_{6} \mathrm{O}_{10}$ glass [31].

It is known that one of the most efficient electrooptic materials, issuing from the Kerr effect, is a nitrobenzene which represents a toxic liquid. The similar is true of perovskite-family ferroelectric crystals [32] which often contain lead ions. These crystals are not convenient due to their ferroelectric properties and, moreover, their growth is more complicated technologically, when compare with the procedures for obtaining the glasses. On the other hand, magnetically ordered solids which are nontransparent in the visible and ultraviolet spectral ranges also belong to the bulk magnetooptic materials [33-36]. In the present study we report the results of studies for the electrooptic and magnetooptic properties of $\mathrm{LiKB}_{4} \mathrm{O}_{7}, \mathrm{Li}_{2} \mathrm{~B}_{6} \mathrm{O}_{10}$, and $\mathrm{LiCsB}_{6} \mathrm{O}_{10}$ glasses.

\section{Experimental}

One of the differences between growth of crystals and synthesis of glasses is that we should reach higher melting temperatures when obtaining the glasses, when compare with those needed for crystallisation. For example, the melting temperature for $\mathrm{LiKB}_{4} \mathrm{O}_{7}$ is equal to $1080 \mathrm{~K}$, while glasssification appears at $1213 \mathrm{~K}$. As a consequence, we kept $\mathrm{LiKB}_{4} \mathrm{O}_{7}$ melt for $6 \mathrm{~h}$ at the temperature of $1213 \mathrm{~K}$ during the process of the glass synthesis. When synthesising the other borate glasses, the melts were overheated at least by $100 \mathrm{~K}$ with respect to the corresponding melting points.

Platinum crucibles were used when preparing the glasses. As a result, we obtained the glasses with the chemical formulae $\mathrm{LiKB}_{4} \mathrm{O}_{7}, \mathrm{Li}_{2} \mathrm{~B}_{6} \mathrm{O}_{10}$, and $\mathrm{LiCsB}_{6} \mathrm{O}_{10}$. The typical average sizes of the samples were $0.7 \times 4 \times 5 \mathrm{~cm}^{3}$. All the glasses were transparent, colourless, and of high enough optical quality. However, some inhomogeneity of the refractive index was detected under visual examination of their optical transparency. In particular, this was peculiar for $\mathrm{Li}_{2} \mathrm{~B}_{6} \mathrm{O}_{10}$ samples. The residual strains in the samples were eliminated when annealing the samples at $680 \mathrm{~K}$.

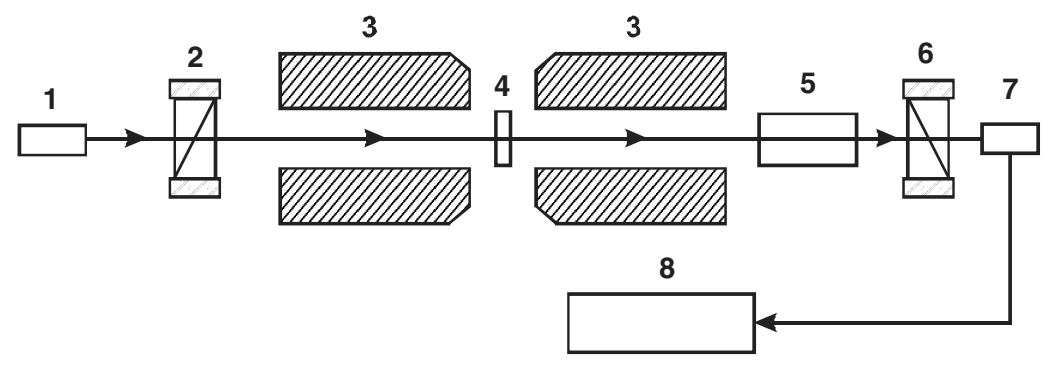

Fig. 1. Experimental setup used for studies of Faraday rotation and electrooptic Kerr effect: 1 - He-Ne laser; 2 and 6 - Glan Thomson polarisers; 3 - electromagnet; 4 - sample; 5 - Faraday modulator; 7 - photomultiplier; 8 - oscilloscope. A quarter-wave plate has been introduced between the electromagnet and the Faraday modulator while studying the electrooptic Kerr effect. 
This procedure had removed the mechanical strains. In order to ascertain that the residual stresses and the corresponding optical birefringence had been surely absent we studied the Faraday rotation at different azimuths of incident light polarisation.

The Faraday rotation and the electrooptic Kerr effect were studied using an experimental setup presented in Fig. 1.

We employed a He-Ne laser (the wavelength of $\lambda=632.8 \mathrm{~nm}$ ) as a source of optical radiation. The Verdet constant $V$ and the Faraday coefficient $\alpha$ were calculated with the formulae

$$
\begin{aligned}
V & =\frac{\rho}{H}, \\
\alpha & =\frac{\rho n \lambda}{\pi H}=\frac{V n \lambda}{\pi},
\end{aligned}
$$

where $\rho=\varphi / d$ is the specific optical rotation, $\varphi$ the total angle of polarisation plane rotation measured in the experiment, $H$ the magnetic field, $d$ the sample thickness along the direction of light propagation, and $n$ the refractive index.

In the case of isotropic centrosymmetric media for which the Pockels effect is forbidden by symmetry, the increment of the birefringence appearing in the electric field $E$ applied normal to the light propagation direction may be written as

$$
\Delta n=\frac{1}{2} n^{3}\left(R_{11}-R_{12}\right) E^{2},
$$

where $R_{11}$ and $R_{12}$ are the components of a fourth-rank polar tensor describing the Kerr effect. While studying experimentally the Kerr effect, we used the same setup depicted in Fig. 1, with a few additional elements. These were a quarter-wave plate allowing us to measure the birefringence increment by a Senarmont technique and a high electric voltage source. The electric field was applied to the sample perpendicular to the direction of light propagation.

\section{Results and discussion}

Dependences of the birefringence increment on the electric field due to the electrooptic Kerr effect measured for the $\mathrm{LiKB}_{4} \mathrm{O}_{7}$ and $\mathrm{LiCsB}_{6} \mathrm{O}_{10}$ glasses are presented in Fig. 2. It is seen that these dependences are well fitted by a quadratic function given by Eq. (3), thus indeed corresponding to the Kerr effect. Using Eq. (3) and the data for the refractive indices derived in our recent work [31] ( $n=1.519 \pm 0.005$ for $\mathrm{LiKB}_{4} \mathrm{O}_{7}$ and $n=1.527 \pm 0.005$ for $\mathrm{LiCsB}_{6} \mathrm{O}_{10}$ ), we have calculated the coefficients of the Kerr effect (see Table 1). Their magnitudes are almost the same for the both compounds. Besides, the value of the electrooptic coefficients in our borate glasses are comparable with those of the nitrobenzene $\left(7.6 \times 10^{-19} \mathrm{~m}^{2} / \mathrm{V}^{2} \quad[32]\right)$, which is often used when constructing high-speed Kerr shutters. However, that liquid is toxic, as already mentioned. Moreover, 
one should remind that liquid-based optical elements are not applicable when powerful lasers are used.

It is worthwhile that the perovskite-type crystals reveal still larger Kerr coefficients $\left(\sim 10^{-15} \mathrm{~m}^{2} / \mathrm{V}^{2}\right.$ [32]), though these ferroelectric crystals stay under instable conditions close to their Curie point. They often contain lead and, moreover, the technology of their growth is usually more complicated than that used for obtaining glasses.

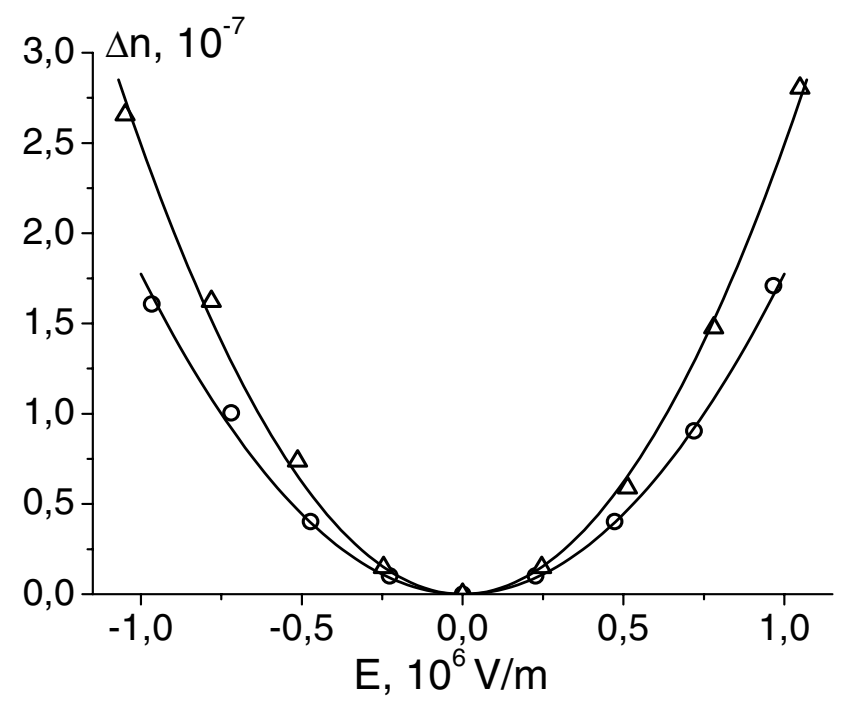

Fig. 2. Dependences of optical birefringence increment on electric field for $\mathrm{LiKB}_{4} \mathrm{O}_{7}$ (open circles) and $\mathrm{LiCsB} 6 \mathrm{O}_{10}$ (open triangles) glasses. Solid curves correspond to fitting of experimental data by a quadratic function given by Eq. (3).

Table 1. Verdet constants, Faraday coefficients and electrooptic Kerr coefficients of the borate glasses.

\begin{tabular}{|l|c|c|c|c|}
\hline $\begin{array}{c}\text { Chemical } \\
\text { composition } \\
\text { of glass }\end{array}$ & $\begin{array}{c}\text { Refrac- } \\
\text { tive } \\
\text { index } n\end{array}$ & $\begin{array}{c}\text { Verdet } \\
\text { constant } \\
V, 10^{-2} \mathrm{deg} / \mathrm{m} \times \mathrm{Oe} \\
(\mathrm{rad} / \mathrm{T} \times \mathrm{m})\end{array}$ & $\begin{array}{c}\text { Faraday } \\
\text { coefficient } \\
\alpha, 10^{-11} \mathrm{Oe}^{-1}\end{array}$ & $\begin{array}{c}\text { Difference of } \\
\text { electrooptic Kerr } \\
\text { coefficients } \\
R_{11}-R_{12}, \\
10^{-19} \mathrm{~m}^{2} / \mathrm{V}^{2}\end{array}$ \\
\hline $\begin{array}{l}\mathrm{Li}_{2} \mathrm{~B}_{4} \mathrm{O}_{7} \\
(\mathrm{Cr} 0.4 \%)\end{array}$ & 1.530 & $\begin{array}{c}2.01 \pm 0.41 \\
(3.51 \pm 0.72)\end{array}$ & $10.82 \pm 2.18$ & - \\
\hline $\mathrm{LiKB}_{4} \mathrm{O}_{7}$ & 1.519 & $\begin{array}{c}2.31 \pm 0.21 \\
(4.03 \pm 0.37)\end{array}$ & $12.31 \pm 1.12$ & $1.05 \pm 0.05$ \\
\hline $\mathrm{LiCsB}_{6} \mathrm{O}_{10}$ & 1.527 & $\begin{array}{c}2.60 \pm 0.37 \\
(4.54 \pm 0.65)\end{array}$ & $13.94 \pm 1.96$ & $1.40 \pm 0.09$ \\
\hline $\mathrm{Li}_{2} \mathrm{~B}_{6} \mathrm{O}_{10}$ & 1.516 & $\begin{array}{c}2.41 \pm 0.24 \\
(4.21 \pm 0.42)\end{array}$ & $12.84 \pm 1.26$ & - \\
\hline
\end{tabular}

4

Ukr. J. Phys. Opt. 2011, V12, №1 

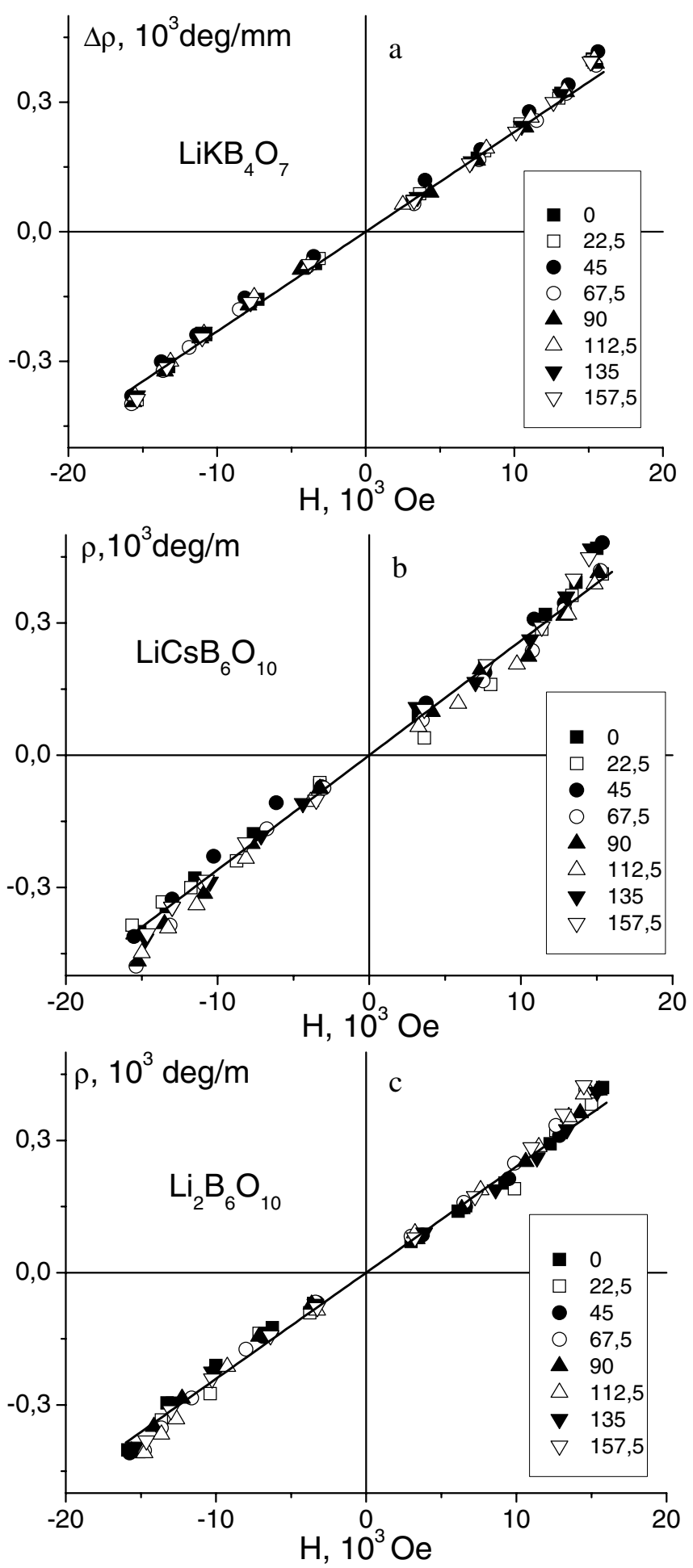

Fig. 3. Faraday rotation of polarisation plane versus magnetic field for $\mathrm{LiKB}_{4} \mathrm{O}_{7}$ (a) $\mathrm{LiCsB}_{6} \mathrm{O}_{10}$ (b) and $\mathrm{Li}_{2} \mathrm{~B}_{6} \mathrm{O}_{10}$ (c) glasses: data points correspond to different polarisation azimuths of the incident light (in deg) and lines to fitting by linear functions. 
The results concerned with the Faraday rotation for $\mathrm{Li}_{2} \mathrm{~B}_{6} \mathrm{O}_{10}, \mathrm{LiCsB}_{6} \mathrm{O}_{10}$, $\mathrm{Li}_{2} \mathrm{~B}_{6} \mathrm{O}_{10}, \mathrm{Li}_{2} \mathrm{~B}_{4} \mathrm{O}_{7}$ and $\mathrm{Li}_{2} \mathrm{~B}_{4} \mathrm{O}_{7}(\mathrm{Cr} 0.4 \%)$ glasses are summarised in Fig. 2 and Table 1. The corresponding measurements have been carried out for different polarisation azimuths of the incident light. Irrespective of the azimuth, the Faraday rotation angles have turned out to be the same, thus testifying an isotropy and homogeneity of the glasses. The Verdet constants of these compounds do not differ essentially. However, the borate glasses $\mathrm{Li}_{2} \mathrm{~B}_{6} \mathrm{O}_{10}$ and $\mathrm{LiCsB}_{6} \mathrm{O}_{10}$ manifest somewhat higher magnetooptic coefficient, while $\mathrm{LiCsB}_{6} \mathrm{O}_{10}$ has higher electrooptic coefficients than those of the $\mathrm{LiKB}_{4} \mathrm{O}_{7}$ glass. It is important to note that the Verdet constant of the glass $\mathrm{Li}_{2} \mathrm{~B}_{4} \mathrm{O}_{7}(\mathrm{Cr} 0.4 \%)$ is almost the same as for the pure $\mathrm{Li}_{2} \mathrm{~B}_{4} \mathrm{O}_{7}$ crystal. Indeed, we have found that the Verdet constant of the latter material is equal to $2.1 \times 10^{-2} \mathrm{deg} / \mathrm{m} \times \mathrm{Oe}$ if the light propagates along the optic axis and the magnetic field is applied along the same direction. Hence, one can conclude that neither crystalline anisotropy nor cation arrangement notably affects both the Kerr and Faraday effects in the borate compounds.

Let us compare the corresponding coefficients with those characterising some of the known magnetooptic materials. In this respect that one can remind that, for example, ZnTe $(V=187 \mathrm{rad} / \mathrm{T} \times \mathrm{m})$ and $\mathrm{Cu}_{2} \mathrm{O}(V=147 \mathrm{rad} / \mathrm{T} \times \mathrm{m})$ [33] belong to compounds having very high Verdet constants. The magnetooptic parameters characteristic for the diluted magnetic semiconductors $\mathrm{Cd}_{1-\mathrm{x}} \mathrm{Mn}_{\mathrm{x}}$ Te are higher [34] (e.g., we have $V=3.38 \mathrm{rad} / \mathrm{G} \times \mathrm{m}$ for $\mathrm{Cd}_{0.62} \mathrm{Mn}_{0.38} \mathrm{Te}$ crystals [35]). The Verdet constant for one of the best magnetooptic materials, $\mathrm{Tb}_{3} \mathrm{Ga}_{5} \mathrm{O}_{12}$ crystal, is equal to $134 \mathrm{rad} / \mathrm{T} \times \mathrm{m}$ at the wavelength of $632.8 \mathrm{~nm}$ and $36.4 \mathrm{rad} / \mathrm{T} \times \mathrm{m}$ at $1053 \mathrm{~nm}$ [36, 37].

The latter parameters are almost two orders higher than those typical for the borate glasses. Nonetheless, the borate glasses reveal some advantages if compare with the crystals mentioned above. Namely, these glasses are easy for obtaining, transparent in a wide spectral range, including the ultraviolet one and, moreover, they are highly resistant to a powerful laser radiation.

\section{Conclusions}

In the present work we have determined the electrooptic Kerr coefficients and the Faraday coefficients for the potassium-, lithium- and caesium-containing borate glasses. It has been shown that, due to transparency of these materials in the ultraviolet spectral range and a high optical damage threshold, these glasses represent attractive materials for the operation of high-power laser radiation in the short-wavelength spectral region.

\section{References}

1. Zhou Guoging, Xu Jun, Chen Xingda, Zhong Heyu, Wang Siting, Xu Ke, Deng Piezhen and Gan Fuxi, 1998. Growth and spectrum of a novel birefringent $\alpha-\mathrm{BaB}_{2} \mathrm{O}_{4}$ crystal. J. Cryst. Growth. 191: 517-519. 
2. Chen $\mathrm{C}, \mathrm{Wu} \mathrm{B}$, Jiang $\mathrm{A}$ and You G, 1985. A new type ultraviolet SHG crystal $\beta-\mathrm{BaB}_{2} \mathrm{O}_{4}$. Sci. Sinica, Ser. B. 28: 235-243.

3. Burak Ya V, Kopko B N, Lysejko I T, Matkovskii A O, Slipetskii R R and Ulmanis U A, 1989. The center of the colour in $\mathrm{Li}_{2} \mathrm{~B}_{4} \mathrm{O}_{7}$ single crystals. Inorg. Mater. 25: 1226-1228.

4. Antonyak O T, Burak Ya V, Lysejko I T, Pidzyrailo M S and Khapko Z A, 1986. Luminescence of the $\mathrm{Li}_{2} \mathrm{~B}_{4} \mathrm{O}_{7}$ single crystals. Opt. Spektrosk. 61: 550-553.

5. Komatsu R, Sugawara T, Sassa K, Sarukura N, Liu Z, Izumida S, Segawa Y, Uda S, Fukuda T and Yamanouchi K, 1997. Growth and ultraviolet application of $\mathrm{Li}_{2} \mathrm{~B}_{4} \mathrm{O}_{7}$ crystals: generation of the fourth and fifth harmonics of $\mathrm{Nd} \mathrm{Y}_{3} \mathrm{Al}_{5} \mathrm{O}_{12}$ lasers. Appl. Phys. Lett. 70: 3492-3494.

6. Ishida $\mathrm{Y}$ and Yajima $\mathrm{T}$, 1987. Characteristics of a new-type SHG crystal $\beta-\mathrm{BaB}_{2} \mathrm{O}_{4}$ in the femtosecond region. Opt. Commun. 62: 197-200.

7. Mori Y, Yap Y K, Kamimura T, Yoshimura M and Sasaki T, 2002. Recent development of nonlinear optical borate crystals for UV generation. Opt. Mater. 19: $1-5$.

8. Petrov V, Rotermund F, Noack F, Komatsu R, Sugawara T and Uda S, 1998. Vacuum ultraviolet application of $\mathrm{Li}_{2} \mathrm{~B}_{4} \mathrm{O}_{7}$ crystals: generation of $100 \mathrm{fs}$ pulses down to $170 \mathrm{~nm}$. J. Appl. Phys. 84: 5887-5892.

9. Petrov V, Noack F, Shen D, Pan F, Shen G, Wang X, Komatsu R and Alex V, 2004. Application of the nonlinear crystal $\mathrm{SrB}_{4} \mathrm{O}_{7}$ for ultra-fast diagnostics converting to wavelengths as short as $125 \mathrm{~nm}$. Opt. Lett. 29: 373-375.

10. Oseledchik Yu, Prosvirnin A, Pisarevskiy A, Starshenko V, Osadchuk V, Belokrys S, Svitanko N, Korol A, Krikunov S and Selevich A, 1995. New nonlinear optical crystals: strontium and lead tetraborates. Opt. Mater. 4: 669-676.

11. Ono Y, Nakaya M, Sugawara T, Watanabe N, Siraishi H, Komatsu R and Kajitani $\mathrm{T}$, 2001. Structural study of $\mathrm{LiKB}_{4} \mathrm{O}_{7}$ and $\mathrm{LiRbB}_{4} \mathrm{O}_{7}$ : new nonlinear optical crystals. J. Cryst. Growth. 229: 472-476.

12. Vlokh R, Dyachok Ya, Krupych O, Burak Ya, Martynyuk-Lototska I, Andrushchak A and Adamiv V, 2003. Study of laser induced damage of borate crystals. Ukr. J. Phys. Opt. 4: 101-104.

13. Cheng L K, Bosenberg W and Tang C L, 1988. Broadly tunable optical parametric oscillation in â- $\mathrm{BaB}_{2} \mathrm{O}_{4}$. Appl. Phys. Lett. 53: 175-177.

14. Bhar G, Das S and Chatterjee U, 1989. Evaluation of beta barium borate crystal for nonlinear devices. Appl. Opt. 28: 202-204.

15. Martynyuk-Lototska I, Dudok T, Krupych O, Adamiv V, Smirnov Ye and Vlokh R, 2004. Acousto-optic diffraction in borate crystals. Ukr. J. Phys. Opt. 5: 111-114.

16. Martynyuk-Lototska I, Mys O, Krupych O, Adamiv V, Burak Ya, Vlokh R and Schranz W, 2004. Elastic, piezooptic and acousto-optic properties of borate crystals $\left(\mathrm{BaB}_{2} \mathrm{O}_{4}, \mathrm{Li}_{2} \mathrm{~B}_{4} \mathrm{O}_{7}\right.$ and $\left.\mathrm{CsLiB}_{6} \mathrm{O}_{10}\right)$. Integr. Ferroelectrics. 63: 99-103.

17. Martynyuk-Lototska I, Dudok T, Mys O and Vlokh R, 2008. Elastic, piezooptic 
and acousto-optic properties of $\mathrm{SrB}_{4} \mathrm{O}_{7}$ and $\mathrm{PbB}_{4} \mathrm{O}_{7}$ crystals. Opt. Mater. 31: 660-667.

18. Martynyuk-Lototska I, Mys O, Dudok T, Adamiv V, Smirnov Ye and Vlokh R, 2008. Acousto-optic interaction in $\alpha-\mathrm{BaB}_{2} \mathrm{O}_{4}$ and $\mathrm{Li}_{2} \mathrm{~B}_{4} \mathrm{O}_{7}$ crystals. Appl. Opt. 47: 3446-3454.

19. Martynyuk-Lototska I, Mys O, Adamiv V, Burak Ya and Vlokh R, 2002. Elastical, piezooptical and acousto-optic properties of lithium tetra borate crystals. Ukr. J. Phys. Opt. 3: 264-266.

20. Andrushchak A, Adamiv V, Krupych O, Martynyuk-Lototska I, Burak Ya and Vlokh R, 2000. Anisotropy of piezo- and elastooptical effect in $\alpha-\mathrm{BaB}_{2} \mathrm{O}_{4}$ crystals. Ferroelectrics. 238: 299-305.

21. Mys $\mathrm{O}, 2008$. Obliquity of the acoustic energy flow in the acousto-optic $\alpha-\mathrm{BaB}_{2} \mathrm{O}_{4}$ and $\mathrm{Li}_{2} \mathrm{~B}_{4} \mathrm{O}_{7}$ crystals. Ukr. J. Phys. Opt. 9: 256-260.

22. Aleksandrov K, Zamkov A, Zaitsev A, Turchin P, Sysoev A and Parfenov A, 2004. Acoustic and acousto-optic properties of lead tetraborate crystals. Fiz. Tverd. Tela. 46: 1586-1587.

23. Mys O, 2009. Acoustooptic and acoustic properties of $\mathrm{KLiB}_{4} \mathrm{O}_{7}$ crystals. Ukr. J. Phys. Opt. 10: 165-174.

24. Dawar A L, Mehta V, Mansingh A and Rajrup, 1997. Acousto-optical studies on $\mathrm{Nd}^{3+}$-doped calcium lithium borate glasses. J. Mat. Sci. Lett. 16: 791-794.

25. Adrianova I I, Aio L G, Asnis L N, Kislitskaya E A and Kokorina V F, 1976. Acousto-optic properties of glasses of the systems As-Ge-Se and As-Ge-Se-Sb. Sov. Phys.: Acoust. 22: 250-251.

26. Kutsenko Ya P, Turyanitsa ID and Tsitrovskii V V, 1976. Acousto-optic properties of glasses of the systems Bi-Sb-O-I. Sov Phys.: Acoust. 22: 253-254.

27. Petrushova O V and Mel'nichenko T N, 1977. Acoustooptic and elastic properties of cadmium-arsenic glasses. Inorg. Mater. 33: 226-229.

28. Abdulhalim I, Pannell C N, Deol R S, Hewak D W, Wylangowski G and Payne D N, 1993. High performance acousto-optic chalcogenide glass based on $\mathrm{Ga}_{2} \mathrm{~S}_{3} \mathrm{La}_{2} \mathrm{~S}_{3}$ systems. J. Non-Crystal. Sol. 164-166: 1251-1254.

29. Kulakova L A, 2006. Acoustooptic interaction in science and applications. Ultrason. 44: e1541-e1548.

30. Kaczmarek S M, 2002. $\mathrm{Li}_{2} \mathrm{~B}_{4} \mathrm{O}_{7}$ glasses doped with $\mathrm{C}, \mathrm{Co}$, Eu and Dy. Opt. Mater. 19: $189-194$.

31. Adamiv V, Tesluk I, Dyachok Ya, Romanyuk G, Krupych O, Mys O, MartynyukLototska I, Burak Ya and Vlokh R, 2010. Synthesis and optical characterisation of $\mathrm{LiKB}_{4} \mathrm{O}_{7}, \mathrm{Li}_{2} \mathrm{~B}_{6} \mathrm{O}_{10}$ and $\mathrm{LiCsB}_{6} \mathrm{O}_{10}$ glasses. Appl. Opt. 49: 5360-5365.

32. Newnham RE, Properties of materials: anisotropy, symmetry, structure. New York: Oxford Univ. Press Inc. (2005).

33. Haussuhl S and Effgen W, 1988. Faraday effect in cubic crystals. Additivity rule and phase transitions. Z. Kristallogr. 183: 153-174.

34. Younghun Hwang, Soo-seong Chung and Youngho Um, 2007. Giant Faraday 
rotation in $\mathrm{Cd}_{1-\mathrm{x}} \mathrm{Mn}_{\mathrm{x}} \mathrm{Te}(0<\mathrm{x}<0.82)$ crystals. Phys. Stat. Sol. (c). 4: 4453-4456.

35. Younghun Hwang, Hyekyeong Kim, Sunglae Cho, Taesoo Kim, Youngho Um, Hyoyeol Park and Gwangsoo Jeen, 2006. Magnetic and magneto-optical properties in diluted magnetic semiconductors: $\mathrm{Cd}_{1-x-y} \mathrm{Mn}_{\mathrm{x}} \mathrm{Fe}_{\mathrm{y}} \mathrm{Te}$ single crystals. J. Magnet. Magn. Mater. 304: e309-e311.

36. Yasuhara R, Tokita S, Kawanaka J, Kawashima T, Kan H, Yagi H, Nozawa H, Yanagitani T, Fujimoto Y, Yoshida H and Nakatsuka M, 2007. Cryogenic temperature characteristics of Verdet constant on terbium gallium garnet ceramics. Opt. Express. 15: 11255-11261.

37. http://www.mt-berlin.com/frames_cryst/descriptions/faraday.htm

Adamenko D., Adamiv V., Klymiv I. and Vlokh R., 2011. Kerr and Faraday effects in borate glasses Ukr.J.Phys.Opt. 12: 1-9.

\footnotetext{
Анотація. Досліджено електрооптичний ефект Кера та магнітооптичний ефект Фарадея в стеклах $\mathrm{LiKB}_{4} \mathrm{O}_{7}, \mathrm{Li}_{2} \mathrm{~B}_{6} \mathrm{O}_{10} \mathrm{i} \mathrm{LiCsB}_{6} \mathrm{O}_{10}$. Для довжини хвилі оптичного випромінювання 632,8 нм отримані значення відповідних коефіцієнтів. Показано, щчо дані сполуки можуть використовуватись як електрооптичні $i$ магнітооптичні матеріали, які є стійкими до потужного оптичного випромінювання $i$ прозорими в ультрафіолетовій області спектру.
} 